\title{
A Retrospective Study on How Psychopathic Traits Differentiate Recidivists From First-Time Female Youth Offenders in Juvenile Detention Centers
}

\author{
Pedro Pechorro, PhDa, Teresa Braga, PhD a, Rachel E. Kahn, $\mathrm{PhD}^{\mathrm{b}}$, \\ Rui Abrunhosa Gonçalves, $\mathrm{PhD}^{\mathrm{a}}$, and Matt Delisi, $\mathrm{PhD}^{\mathrm{c}}$ \\ aschool of Psychology, University of Minho, Braga, Portugal; 'band Ridge Secure Treatment Center, \\ Madison, Wisconsin, USA; 'Department of Sociology, lowa State University, Ames, lowa, USA
}

\begin{abstract}
The aim of the present study was to analyze the relation between recidivism and self-reported psychopathic traits, more specifically the callous-unemotional, impulsivity, and narcissism dimensions of the psychopathy construct among female juvenile delinquents. The Antisocial Process Screening Device-Self-Report (APSD-SR) and other self-report psychometric instruments (i.e., Inventory of Callous-Unemotional Traits [ICU], Barratt Impulsiveness Scale, version 11 [BIS-11], Narcissistic Personality Inventory-13 [NPI-13]) independently measuring the different dimensions of psychopathy were completed by a sample of incarcerated female juvenile offenders $(\mathrm{N}=81)$ that were retrospectively classified as first-time offenders versus recidivists. The only statistically significant relation between recidivism and psychopathic traits found was with narcissism, namely with the Grandiose/Exhibitionism and the Entitlement/Exploitativeness dimensions of the NPI-13. Our results argue for some utility of self-reported psychopathic traits in retrospectively predicting recidivism among female juvenile delinquents.
\end{abstract}

\section{KEYWORDS}

crime; female; juvenile delinquency; psychopathic traits; recidivism

Psychopathy is a personality disorder comprised of a constellation of interpersonal, affective, and behavioral personality features. Individuals with high levels of psychopathic traits are characterized by a superficial and manipulative interpersonal style, a profound lack of empathy and remorse, frequent impulsivity and irresponsibility, and socially deviant behavior or antisociality (Hare, 2003). These characteristics significantly increase an individual's likelihood of antisocial conduct and involvement in the juvenile and criminal justice systems. Offenders with psychopathy have been shown to have an earlier onset of criminal behavior and greater criminal versatility (Roberts \& Coid, 2007; Tuente, de Vogel, \& Stam, 2014), are responsible for more severe forms of crime (Coid \& Yang, 2011; Porter, Woodworth, Earle, Drugge, \& Boer, 2003), and show particularly high rates of criminal recidivism (Edens, 
Campbell, \& Weir, 2007; Hare, 2003; Walters, 2003). Indeed, researchers using data from multiple nations have shown that psychopathic features are robustly and positively associated with more extensive, serious, and violent criminal careers (Connolly et al., 2017; Corrado, McCuish, Hart, \& DeLisi, 2015; DeLisi et al., 2014; Kahn, Byrd, \& Pardini, 2013; Theobald, Farrington, Coid, \& Piquero, 2016; Vaughn, Howard, \& DeLisi, 2008).

Due to these empirical associations, psychopathic traits have long been examined as a predictor of recidivism among adult (e.g., Hare, 1996, 2003; Salekin, Rogers, \& Sewell, 1996) and youth offender populations (e.g., Asscher et al., 2011; Edens et al., 2007). In criminology, most definitions of recidivism resort to its etymological origins - that is, to fall back or relapse. Hence, criminal recidivism has been commonly described as the relapse of an individual into criminal behavior after receiving a correctional intervention (Loeber, Jennings, Ahonen, Piquero, \& Farrington, 2017; Maltz, 1984; Zara \& Farrington, 2016). For adult populations, research supports a strong link between psychopathic traits and recidivism (e.g., Boduszek, Debowska, Dhingra, \& DeLisi, 2016; Hare, 1996, 2003; McCuish, Corrado, Hart, \& DeLisi, 2015; Walters, 2003). As for juvenile populations, the research is more equivocal. While some studies have found an association between psychopathic features and criminal recidivism (e.g., Edens et al., 2007; Olver, Stockdale, \& Wormith, 2009), other work seems to suggest the robustness of this relation may differ depending on the gender of the participant (e.g., Rowe, 2002; Schmidt, McKinnon, Chattha, \& Brownlee, 2006), method of assessment (e.g., Colins, van Damme, Andershed, Fanti, \& DeLisi, 2017; Douglas, Epstein, \& Poythress, 2008), or which dimensions of psychopathy are being measured (e.g., Corrado, Vincent, Hart, \& Cohen, 2004; Vaughn, Newhill, DeLisi, Beaver, \& Howard, 2008; Vitacco, Neumann, \& Jackson, 2005). Thus, the aim of the current study is to examine the association of female psychopathy with recidivism using self-report measures of psychopathic traits, and to examine the underlying dimensions of psychopathy (i.e., narcissism, impulsivity, and callous-unemotional traits) with juvenile recidivism.

\section{Self-report measures of psychopathic traits and recidivism}

Self-report measures of psychopathic traits have been criticized as having a heightened vulnerability to response distortion due to the deception or lack of insight by an offender population (Edens, Hart, Johnson, Johnson, \& Olver, 2000; Kroner \& Loza, 2001). Yet there is evidence to support the validity of self-report measures of psychopathy with recent work suggesting self-reported psychopathic traits do not differ from an informant report when no direct consequences are present (Miller, Jones, \& Lynam, 2011). Another study found that self-report psychopathy instruments were similar to clinician ratings of psychopathy in their ability to predict institutional misconduct (Edens, Poythress, \& Lilienfeld, 1999). 
The results on the predictive validity of self-report assessments of psychopathy in detained adolescent samples are mixed. For example, some earlier studies suggested that self-report measures of psychopathy, such as the Antisocial Process Screening Device (APSD; Frick \& Hare, 2001) and the Child Psychopathy Scale (CPS; Lynam, 1997), outperform the clinical rating of the Psychopathy Checklist Youth Version (PCL:YV; Forth, Kosson, \& Hare, 2003) in predicting recidivism among a detained male adolescent sample (Douglas et al., 2008). With a mixed-gender sample of detained adolescents, Salekin (2008) found the total score on the APSD was predictive of general recidivism over a three- to four-year time span. However, a more recent study found scores on the APSD were not predictive of recidivism in a sample of detained female adolescents after a sixmonth follow-up period (Colins et al., 2017). A meta-analysis examined whether the association between psychopathy and recidivism differed based on the method used for assessing psychopathic traits-expert rating versus self-report (Asscher et al., 2011). Findings revealed the method of assessment was a significant moderator of the psychopathy-recidivism association, with clinical judgments (or expert ratings) being more strongly linked to recidivism than self-report measures. This meta-analysis also highlighted, however, that only 9 of the studies included examined self-report assessments of psychopathic traits, compared to the 29 studies that utilized clinical judgments (Asscher et al., 2011).

\section{Psychopathic traits and recidivism among females}

The construct of psychopathy as well as the link between psychopathy and criminality seems to differ for females compared to males. For instance, mental health professionals rate psychopathic women as less antisocial than psychopathic men (Hazelwood, 2006), but women with psychopathy are characterized by greater emotional and self-concept instability and manipulation than their male counterparts (Kreis \& Cooke, 2011). Furthermore, directly comparing women and men with psychopathy on their criminal histories, de Vogel and Lancel (2016) found several gender differences, with women committing more fraud and their criminal acts more often the result of relational frustration. In addition, women with psychopathy demonstrated less physical violence during treatment but were often more manipulative and self-destructive than their male counterparts. As for criminal recidivism, relatively few studies have evaluated the capacity of psychopathic traits to predict recidivism, particularly among adolescent girls. However, those that have generally do not lend support for this relation. For instance, Odgers, Reppucci, and Moretti (2005) found that psychopathy did not predict future offending in a sample of 62 adolescent female offenders followed up at least three months after their release from a correctional facility. Likewise, Vincent, Odgers, McCormick, and Corrado (2008) also concluded that psychopathy did not predict recidivism in a sample of 55 female juvenile offenders using a prospective 4.5-year follow-up. In contrast, Rowe (2002) found a significant and 
robust relationship between psychopathy and recidivism $(r=.58)$ among 81 adolescent females followed up for approximately two years. It should be noted, however, that Rowe's (2002) study was identified as an outlier in a meta-analytic review examining the Psychopathy Checklist Youth Version (PCL:YV; Forth et al., 2003) and its link to recidivism (Edens et al., 2007). After removing this outlier study, the results for the female samples no longer showed evidence of heterogeneity and the mean effect size was attenuated and became nonsignificant. However, this meta-analysis included only five female samples and focused exclusively on the PCL:YV. The historical gender gap in offending, with girls showing much lower levels of crime involvement than boys (see Lanctôt \& Le Blanc, 2002, for a review), may account for the emphasis on male over female criminality and recidivism research. Given that official statistics have revealed a gradual decrease in the male-female ratio of crime involvement (Goodkind, Wallace, Shook, Bachman, \& O'Malley, 2009), further research focusing on criminal recidivism, and its association with psychopathic traits, in female populations is warranted.

\section{Specific psychopathic facets and recidivism}

Some research suggests the link between psychopathy and future offending may be explained primarily by the behavioral symptoms of psychopathy (e.g., Corrado et al., 2004; Langström \& Grann, 2002), that is, the social deviance or antisocial components of psychopathy. For example, Walters, Knight, Grann, and Dahle (2008) revealed that the antisocial facet of psychopathy, as measured by the PCL-R, achieved incremental validity relative to all other facets (interpersonal, affective, and lifestyle). However, the conceptual framework that includes the antisocial behavior in the psychopathy construct (Hare, 2003) has been criticized for its tautological nature. That is, it has been argued that antisocial behavior is an outcome and not a core trait of psychopathy (e.g., Cooke \& Michie, 2001).

Moreover, the common conceptual framework of psychopathy has been criticized by scholars who suggest the four-factor construct of psychopathy may not adequately capture the manifestation of psychopathy in females (e.g., McKeown, 2010). Lending support to this criticism, relative research has produced a different factor structure of psychopathy for females (e.g., Jackson, Rogers, Neumann, \& Lambert, 2002) while simultaneously revealing that females tend to score lower on measures of psychopathy compared to males (e.g., Wynn, Høiseth, \& Pettersen, 2012). Overall, concerns about the inclusion of antisocial behavior within the construct of psychopathy have led to the exclusion of antisocial items in some measures of psychopathy (e.g., Andershed, Kerr, Stattin, \& Levander, 2002; Boduszek \& Debowska, 2016) and highlighted the importance of focusing on the impulsive, interpersonal, and affective dimensions of the construct (Cooke \& Michie, 2001). This is 
particularly important when considering gender differences in psychopathy since females have less severe criminal careers than males, and thus the components of the disorder beyond antisocial items are potentially more important.

In youth populations, increasing research has narrowed in on the importance of the affective traits of psychopathy, termed callous-unemotional (CU) traits. High levels of these traits have been linked to a particularly important subgroup of antisocial youth: those who tend to engage in more severe and aggressive antisocial behaviors, show poor treatment responses, and have an increased risk to develop psychopathy in adulthood compared to antisocial youth with normative levels of CU traits (see Frick, Ray, Thornton, \& Kahn, 2014, for a review). Recently, CU traits were recognized in the fifth edition of the Diagnostic and Statistical Manual of Mental Disorders (DSM-5; American Psychiatric Association, 2013) as a specifier for the diagnosis of conduct disorder, and designated as "with Limited Prosocial Emotions." This specifier is intended to characterize youth diagnosed with conduct disorder who also show a lack of remorse or guilt, callousness or lack of empathy, unconcern about performance in important activities, or shallowness or deficient affect. With regard to the ability of CU traits to predict recidivism, some recent studies revealed that $\mathrm{CU}$ traits predict various recidivism outcomes above and beyond factors such as past antisocial behavior among young men (Kahn et al., 2013), adolescent boys (Kimonis, Kennealy, \& Goulter, 2016), and female offenders (Thomson, Towl, \& Centifanti, 2015), as well as more specific antisocial outcomes such as general aggression (e.g., Feilhauer, Cima, \& Arntz, 2012; Ray, Pechorro, \& Gonçalves, 2016).

Other features of psychopathy, such as impulsivity and narcissism, have also been linked to antisocial behavior or recidivism. For example, a metaanalysis of 21 studies indicated that greater impulsivity was associated with a wide variety of risk behaviors such as alcohol consumption and aggression (Vasconcelos, Malloy-Diniz, \& Correa, 2012). However, among a sample of detained girls, Colins et al. (2017), concluded that the impulsivity subscale of the APSD was not related to various antisocial outcomes after controlling for past offenses, aggression, and alcohol or drug use

When examining narcissism specifically, studies have found significant associations between narcissism and several antisocial indicators, such as age of criminal onset, crime seriousness, alcohol and cannabis use, and self-reported delinquency (Golmaryami \& Barry, 2010; Pechorro, Gentile, Ray, Nunes, \& Gonçalves, 2016; Vaughn, Newhill, et al., 2008b). As the aforementioned research implies, the relative importance of unique psychopathic traits in predicting recidivism needs further analyses.

\section{Current study}

In summary, few studies have examined whether self-reported psychopathic traits predict recidivism among juvenile female offenders. Furthermore, we 
are unaware of studies in southern European countries like Portugal that have explored psychopathy as a risk factor for female juvenile recidivism. Thus, the aim of this study was to analyze the relation between self-reported psychopathic traits and recidivism in female delinquents; specifically, whether callous-unemotional, impulsivity, and narcissism dimensions of the psychopathy construct retrospectively predict recidivism among a sample of incarcerated female juvenile delinquents after controlling for number of previous crimes and age of first incarceration. We also examined the relation between subcomponents of psychopathy and recidivism using broader measures of impulsivity, narcissism, and CU traits.

\section{Method}

\section{Participants}

Female inmates from the three juvenile detention centers managed by the General Directorate of Reintegration and Prison Services of the Portuguese Ministry of Justice (DGRSP-MJ) that handle female youths voluntarily agreed to participate in the current study $(N=81)$. Incarceration into juvenile detention centers is the most severe measure that can be taken by Portuguese courts. The three detention centers that collaborated in the present study are considered low to medium security. Participants ranged in age from 14 to 18 years old $(M=16.35 ; S D=1.20)$, were primarily from an urban background $(97.5 \%)$, and were comprised of white Europeans (59.3\%), black Africans (19.8\%), mixed race South Americans (12.3\%), and members of other ethnic minorities (8.6\%). About $87.7 \%$ were Portuguese nationals and $12.3 \%$ were foreigners. The participants, on average, became involved in crime at an early age $(M=12.12$ years, $S D=1.62$ years $)$, and most were detained prior to the age of $16(M=15.86$ years, $S D=1.18$ years) due to having committed serious or violent crimes (e.g., robbery, assault).

\section{Instruments}

The Antisocial Process Screening Device (APSD; Frick \& Hare, 2001) self-report version (Caputo, Frick, \& Brosky, 1999) is a multidimensional 20-item measure designed to assess psychopathic traits in adolescents. It was modeled after the Psychopathy Checklist (Forth et al., 2003; Hare, 2003). Each item is scored on a 3-point ordinal scale ranging from "Never" to "Often." The total score, as well as each dimension score, is obtained by adding the respective items. The APSD consists of three factors: Callous-Unemotional, Narcissism, and Impulsivity; higher scores indicate higher psychopathic traits. The Portuguese version of the APSD-SR (Pechorro, Hidalgo, Nunes, \& Jiménez, 2016) was used for the current study. The internal consistency for the current study, estimated by 
Cronbach's alpha $(\alpha)$, was: APSD-SR total $=.74$; Callous-Unemotional $=.52$; Impulsivity $=.65$; and Narcissism $=.74$.

The Inventory of Callous-Unemotional Traits (ICU; Essau, Sasagawa, \& Frick, 2006) is a 24-item self-report scale designed to assess callous and unemotional traits in youth derived from the callous-unemotional (CU) subscale of the APSD (Frick \& Hare, 2001). Each item is scored on a 4-point scale ranging from "Not at all true" to "Definitely true." Scores are calculated by reverse-scoring the positively worded items and then summing the items to obtain a total score. Using confirmatory factor analysis, three independent factors have emerged: Callousness, Unemotional, and Uncaring. All items also load onto a general callous-unemotional factor (Kimonis et al., 2008). Higher scores indicate an increased presence of CU traits. The Portuguese version of the ICU (Pechorro, Ray, Barroso, Maroco, \& Gonçalves, 2016) was used. The internal consistency for the current study was: ICU total $\alpha=.84$; Callousness $\alpha=.81$; Uncaring $\alpha=.81$; and Unemotional $\alpha=.75$.

The Barratt Impulsiveness Scale, version 11 (BIS-11; Patton, Stanford, \& Barratt, 1995) is a 30-item self-report questionnaire designed to measure impulsiveness. Each item is scored on a 4-point ordinal scale ranging from "Rarely/ never" to "Almost always/always." The BIS-11 contains six subscales that correspond to the six first-order factors, namely (a) attention, (b) cognitive instability, (c) motor, (d) perseverance, (e) self-control, and (f) cognitive complexity. The total score, as well as each dimension score, is obtained by adding the respective items, but some items are scored in reverse order to avoid a response bias. The items are summed with higher BIS-11 scores, indicating higher impulsivity. The Portuguese version of the BIS-11 (Pechorro, Maroco, Ray, \& Gonçalves, 2015), more specifically a reduced short version composed of three dimensions and especially adapted for adolescents, was used (Pechorro, Oliveira, Gonçalves, \& Jesus, 2018). The internal consistency for the current study was: BIS-11 total $\alpha=.81$; Attention $\alpha=.62$; Motor $\alpha=87$; and Self-Control $\alpha=.71$.

The Narcissistic Personality Inventory-13 (NPI-13; Gentile et al., 2013) is a short version derived from the original Narcissistic Personality Inventory (Raskin \& Terry, 1988). It consists of 13 pairs of statements, among which one is considered to confirm an attitude of narcissism and the other is not (coded 1 and 0 , respectively). Respondents are instructed to indicate the item that best describes them. Gentile et al. (2013) developed the NPI-13 specifically to maintain a three-factor structure: Leadership/Authority (LA), Grandiose/ Exhibitionism (GE), and Entitlement/Exploitativeness (EE). Higher scores indicate higher levels of narcissism. The Portuguese version of the NPI-13 was used (Pechorro et al., 2016). The internal consistency for the current study, estimated by the Kuder-Richardson coefficient (KR; i.e., alpha for dichotomous items), was $\mathrm{NPI}-13$ total $=.79, \mathrm{LA}=.71, \mathrm{GE}=.65$, and $\mathrm{EE}=.53$.

A questionnaire was constructed by the authors to describe the sociodemographic and criminal characteristics of the participants. It included questions about 
participants' age, ethnic group, rural versus urban origin, years of schooling completed, socioeconomic status, nationality, taking of psychiatric medication, age of first transgression, age of first problem with the law and age of first incarceration in a juvenile detention center, violent crimes, number of criminal cases, number of crimes, criminal diversity, cannabis use, cocaine or heroin use, and alcohol abuse (these last three coded as 5-point ordinal variables). Socioeconomic status (SES) was measured by a combination of the parent's level of education and profession, appropriate to the Portuguese context (Simões, 2000).

Official criminal recidivism data (i.e., charges and convictions) were obtained from a database of the General Directorate of Reintegration and Prison Services, Ministry of Justice (DGRSP-MJ). Participants with at least one prior conviction that previously received intervention by the DGRSP (that is, any conviction, not necessarily a conviction leading to incarceration) were considered recidivists. First-time offenders with no previous convictions were considered nonrecidivists.

\section{Procedures}

Authorization to assess youths for this research project was obtained from the DGRSP-MJ. The detainees, from the three existing Portuguese Juvenile Detention Centers that admit female youths, were informed about the nature of the study and asked to voluntarily participate. The participation rate was approximately $92 \%$. Of those who did not participate, $5 \%$ refused to participate, $2 \%$ did not understand the Portuguese language, and $1 \%$ could not participate due to security issues. Some of the sociodemographic information was obtained from self-reports, but institutional files were also used to complement the information obtained (e.g., prior criminal activity and detentions, psychiatric medication). All measures were administered by means of individual face-to-face interviews in an appropriate setting and it was stressed that there were no right or wrong answers.

\section{Analytical plan}

The data was analyzed using SPSS v24 (IBM SPSS, 2016). Binary logistic regression analyses were used to test associations between the predictive variables (dimensions of psychopathic traits) and the dependent variable (recidivism status). Scale totals were not included in the regression models to avoid multicollinearity. Analyses of variance (ANOVAs), Mann-Whitney $U$ tests, and chisquare tests were used to compare groups when the dependent variables were scale, ordinal or nominal, respectively. A $p$ value of $<.05$ was used as an indicator of statistical significance (Aron, Coups, \& Aron, 2013). Cronbach's alphas were considered adequate if above .70, marginal if between .60 and .69, and insufficient if below .60 (DeVellis, 1991; Nunnally \& Bernstein, 1994). 


\section{Results}

In the initial phase of data analysis, the sociodemographic and criminal variables were analyzed. About $80.2 \%$ of the participants were recidivists or repeat offenders $(n=65)$ and $19.8 \%$ were nonrecidivist or first-time offenders $(n=16)$. No statistically significant differences between recidivists and nonrecidivists were found in terms of years of age $(F=1.681, p=.20)$, SES $(U=339.0, p=.36)$, ethnicity $\left(\chi^{2}=2.046 ; p=.17\right)$, use of psychiatric medication $\left(\chi^{2}=1.756 ; p=.26\right)$, rural versus urban origin $\left(\chi^{2}=.505\right.$; $p=.99)$, or nationality $\left(\chi^{2}=2.808 ; p=.27\right)$. The absence of differences indicated the two groups did not differ on any of these variables.

Table 1 displays the correlations between the main variables used in the present investigation.

Table 2 displays two binary logistic regression coefficients for recidivism status. The APSD-SR subscales and ICU subscales are entered as predictors in two independent models after controlling for number of crimes and age of first incarceration in a juvenile detention center because these are particularly important variables in terms of defining offending (Whitten, McGee, Homel, Farrington, \& Ttofi, 2017). The APSD-SR and the ICU total scores were not included in the equations to avoid multicollinearity. None of the APSD-SR and ICU subscales reached statistical significance.

Table 3 presents another two binary logistic regression coefficients for recidivism status. The BIS-11 subscales and the NPI-13 subscales are entered as predictors in two independent models after controlling again for number of crimes and age of first incarceration in a juvenile detention center. None of the BIS-11 subscales reached statistical significance. For the NPI-13, both the Grandiose/Exhibitionism and the Entitlement/Exploitativeness subscales reached statistical significance.

\section{Discussion}

Our study is the first to examine the relationship between recidivism and the different components of psychopathy among a sample of Portuguese female youth involved in the juvenile justice system. In addition, this study extends understanding of self-report measures of juvenile psychopathy while considering cultural and ethnic differences. Overall, the findings of our study suggest some utility-albeit somewhat limited-of the different self-report assessments of psychopathy and its related components in distinguishing between recidivists and nonrecidivists among a sample of incarcerated female youth.

The only measure that distinguished between recidivists and nonrecidivists after controlling for number of crimes and age of first incarceration in a juvenile detention center was the NPI-13. This suggests that narcissism, as 


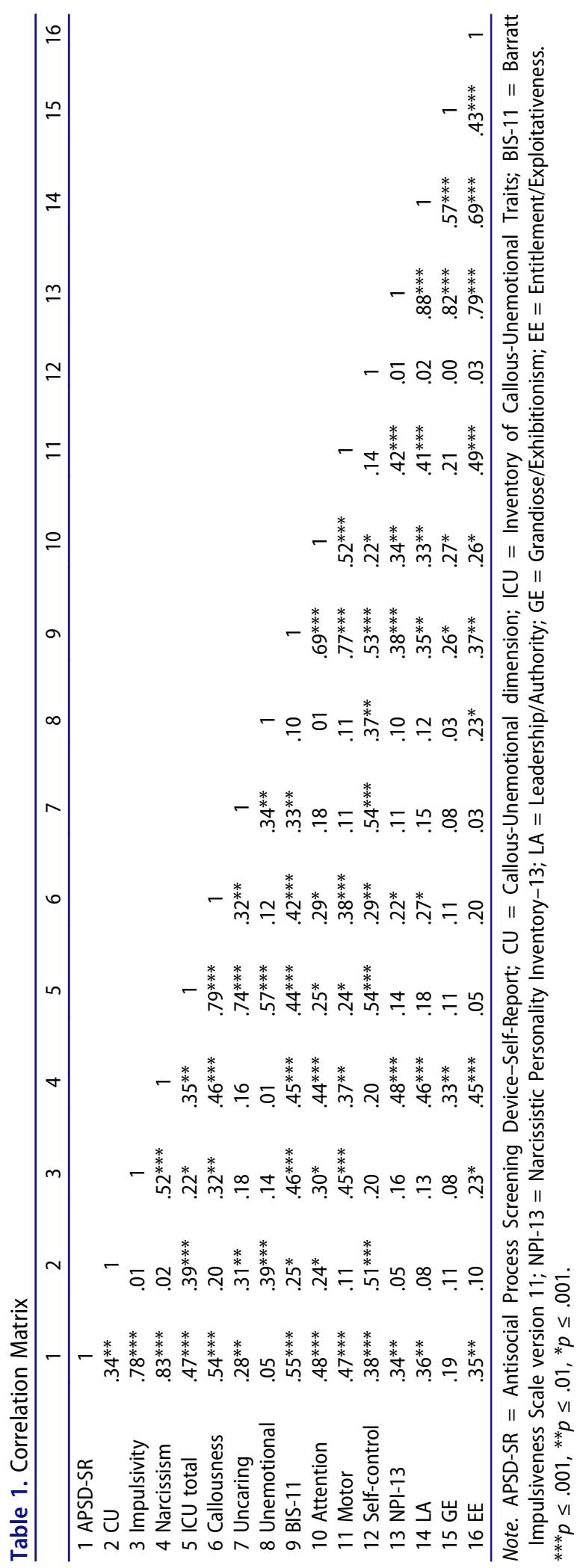


Table 2. Logistic Regression Coefficients of APSD-SR and ICU Predicting Recidivism

\begin{tabular}{lrrrrr}
\hline & \multicolumn{1}{c}{ B } & SE & Wald & Exp(B) & $p$ value \\
\hline APSD-SR & & & & & \\
1st block & & & & & \\
NC & 1.198 & .351 & 11.655 & 3.312 & $p=.001$ \\
AFI & .836 & .406 & 4.247 & 2.307 & $p=.039$ \\
$\quad$ Constant & -15.707 & 6.816 & 5.311 & .000 & $p=.021$ \\
2nd block & & & & & \\
NC & 1.265 & .376 & 11.305 & 3.542 & $p=.001$ \\
AFI & .809 & .420 & 3.700 & 2.245 & $p=.054$ \\
CU & .084 & .249 & .113 & 1.087 & $p=.737$ \\
Impulsivity & -.272 & .240 & 1.285 & .762 & $p=.257$ \\
Narcissism & .098 & .182 & .291 & 1.103 & $p=.590$ \\
Constant & -14.954 & 7.293 & 4.205 & .000 & $p=.040$ \\
ICU & & & & & \\
1st block & & & & & \\
NC & .198 & .351 & 11.655 & 3.312 & $p=.001$ \\
AFI & .836 & .406 & 4.247 & 2.307 & $p=.039$ \\
Constant & -15.707 & 6.816 & 5.311 & .000 & $p=.021$ \\
2nd block & 1.530 & & & & \\
NC & 1.338 & .439 & 12.147 & 4.618 & $p \leq .001$ \\
AFI & .190 & .130 & 5.914 & 3.810 & $p=.015$ \\
Callousness & .131 & .155 & 2.142 & 1.210 & $p=.143$ \\
Uncaring & .069 & .177 & .717 & 1.140 & $p=.397$ \\
Unemotional & -28.069 & 10.477 & 7.178 & 1.072 & $p=.695$ \\
Constant & & .000 & $p=.007$ \\
\hline
\end{tabular}

Note. APSD-SR = Antisocial Process Screening Device-Self-Report; CU = Callous-Unemotional; ICU = Inventory of Callous-Unemotional Traits; $\mathrm{NC}=$ Number of crimes; $\mathrm{AFI}=$ Age of first incarceration.

measured by the NPI-13, may be a relevant indicator for identifying females at risk for recidivism. More specifically, the Grandiose/Exhibitionism and the Entitlement/Exploitativeness dimensions of the NPI-13 were significantly associated with recidivism. Although the NPI-13 was not developed to assess psychopathy per se, it does assess characteristics that tap into the interpersonal factor of this multidimensional construct. Research examining the relation between the NPI and juvenile recidivism has been somewhat limited, but this self-report measure has been examined in terms of its criterion validity to other antisocial outcomes. The child version of the NPI (Barry, Frick, \& Killian, 2003) was found to be a significant predictor of self-report delinquency (Barry, Grafeman, Adler, \& Pickard, 2007) and peer-nominated relational aggression (Golmaryami \& Barry, 2010) for adolescents who had withdrawn from school. More recently (Pechorro, Gentile et al., 2016) found significant associations between the NPI, especially two of its short forms (NPI-16 and NPI-13), with age of criminal onset, crime seriousness, conduct disorder symptoms, alcohol abuse, and cannabis use among males.

Given the absence of significant associations between the APSD and recidivism in this sample, it is worth considering that self-report measures of psychopathy were not originally designed to be used in isolation within forensic settings and were largely developed to assess psychopathic traits in community settings (Brinkley, Schmitt, Smith, \& Newman, 2001). Another 
Table 3. Logistic Regression Coefficients of the BIS-11 and NPI-13 Predicting Recidivism

\begin{tabular}{|c|c|c|c|c|c|}
\hline & $B$ & SE & Wald & $\operatorname{Exp}(B)$ & $p$ value \\
\hline \multicolumn{6}{|l|}{ BIS-11 } \\
\hline \multicolumn{6}{|l|}{ 1st block } \\
\hline NC & 1.198 & .351 & 11.655 & 3.312 & $p=.001$ \\
\hline $\mathrm{AFI}$ & .836 & .406 & 4.247 & 2.307 & $p=.039$ \\
\hline Constant & -15.707 & 6.816 & 5.311 & .000 & $p=.021$ \\
\hline \multicolumn{6}{|l|}{ 2nd block } \\
\hline NC & 1.236 & .368 & 11.271 & 3.440 & $p=.001$ \\
\hline $\mathrm{AFI}$ & 1.019 & .481 & 4.501 & 2.772 & $p=.034$ \\
\hline Attention & -.211 & .186 & 1.278 & .810 & $p=.258$ \\
\hline Motor & -.057 & .127 & .206 & .944 & $p=.650$ \\
\hline Self-Control & .169 & .137 & 1.525 & 1.185 & $p=.217$ \\
\hline Constant & -17.441 & 8.319 & 4.395 & .000 & $p=.036$ \\
\hline \multicolumn{6}{|l|}{ NPI-13 } \\
\hline \multicolumn{6}{|l|}{ 1st block } \\
\hline NC & 1.198 & .351 & 11.655 & 3.312 & $p=.001$ \\
\hline $\mathrm{AFI}$ & .836 & .406 & 4.247 & 2.307 & $p=.039$ \\
\hline Constant & -15.707 & 6.816 & 5.311 & .000 & $p=.021$ \\
\hline \multicolumn{6}{|l|}{ 2nd block } \\
\hline NC & 1.461 & .439 & 11.087 & 4.308 & $p=.001$ \\
\hline $\mathrm{AFI}$ & 1.668 & .746 & 4.995 & 5.303 & $p=.025$ \\
\hline LA & .152 & .562 & .073 & 1.164 & $p=.787$ \\
\hline GE & -1.894 & .668 & 8.050 & .150 & $p=.005$ \\
\hline EE & 1.351 & .642 & 4.434 & 3.861 & $p=.035$ \\
\hline Constant & -27.814 & 12.108 & 5.277 & .000 & $p=.022$ \\
\hline
\end{tabular}

explanation for the differences across self-report and clinical assessments in predicting recidivism is that measures like the PCL:YV include antisocial history, which significantly enhances its utility in predicting recidivism, while most self-report measures capture the underlying trait-like aspects of psychopathy. As a matter of fact, research suggests that the behavioral component of the PCL:YV is the best predictor of recidivism (Boduszek \& Debowska, 2016; Corrado et al., 2004). In summary, our exclusive use of self-report instruments may be one explanation for the limited findings in the current study with regard to aspects of psychopathy not distinguishing between recidivists and nonrecidivists.

Another possible explanation is that the restricted range on recidivism limited our ability to identify associations between psychopathy and continued antisocial conduct. Indeed, over $80 \%$ of the current sample was classified as recidivists. Thus, future research with larger control groups of nonrecidivists is needed to examine the relationship between self-report measures of psychopathic traits and recidivism among samples of juvenile offenders with a wider range of risk for recidivism and psychopathic traits.

The findings from the current study can be viewed as important, but they should be considered within the context of the several limitations. As noted above, there was limited variability on the recidivism outcome, and the data 
collection procedures in the current study precluded the use of a more nuanced measure of recidivism (e.g., time to re-arrest). The current study focused on a sample of incarcerated female juveniles in Portugal, therefore, it is not clear how the current study findings extend to other cultures or ethnicities. The small size and disproportionate group sizes can also be considered potential issues and may have limited the findings. Also, the current study was retrospective in terms of identifying the outcome. The approach taken in the current study was to distinguish between those classified as recidivists and nonrecidivists, but this approach does not allow for any causal conclusions to be drawn and does not enable predictive utility of these measures to truly be assessed. Another limitation was related to the fact that the psychometric instruments used have been predominantly validated on male samples, and some subscales (e.g., the EE subscale of the NPI-13) presented low reliability values that may have interfered with our findings. Finally, recidivism was measured using official records based on convictions. There are several ways to assess recidivism including self-report, arrest, and charge. The use of conviction may reflect extralegal factors (e.g., ethnicity, social class, and access to quality legal counsel) that potentially influence court outcomes.

Our study, despite these limitations, sheds more light on a relatively unstudied area-comparing dimensions of psychopathic personality via self-report as indicators of recidivism among female youths from a forensic context. The findings from the current study suggest narcissism may play a role in predicting recidivism among female offenders. It is important to mention that researchers have consistently recognized prior offending as one of the best predictors of recidivism (Cottle, Lee, \& Heilbrun, 2001), but the explanatory power of prior behavior in itself is somewhat limited because, while prior offending consistently predicts future offending, it does not explain why some individuals are more likely to recidivate or offend in the first place. By delving into the constituent parts of psychopathy, the specific features-such as narcissism-that drive continued conduct problems can be identified not only for research purposes but also to serve as targets for treatment and supervision.

\section{Acknowledgment}

We wish to thank the following Portuguese juvenile detention centers for their collaboration: Bela Vista, Navarro de Paiva, and Santa Clara.

\section{Funding}

This study was supported by the Portuguese Foundation for Science and Technology (FCT; Grant SFRH/BPD/86666/2012), with cofinancing of the European Social Fund (POPH/FSE), the Portuguese Ministry of Science (MCTES), and the PT2020 Partnership Agreement (UID/ PSI/01662/2013). 


\section{References}

American Psychiatric Association. (2013). Diagnostic and statistical manual of mental disorders (5th ed.). Washington, D.C.: Author.

Andershed, H., Kerr, M., Stattin, H., \& Levander, S. (2002). Psychopathic traits in nonreferred youths: Initial test of a new assessment tool. In E. Blaauw \& L. Sheridan (Eds.), Psychopaths: Current international perspectives (pp. 131-158). Haag, The Netherlands: Elsevier.

Aron, A., Coups, E., \& Aron, E. (2013). Statistics for psychology (6th ed.). New York, NY: Pearson.

Asscher, J. J., van Vugt, E. S., Stams, G. J., Dekovic, M., Eichelsheim, I. V., \& Yousfi, S. (2011). The relationship between juvenile psychopathic traits, delinquency and (violent) recidivism: A meta-analysis. Journal of Child Psychology and Psychiatry, 52, 1134-1143. doi:10.1111/j.1469-7610.2011.02412.x

Barry, C., Grafeman, S., Adler, K., \& Pickard, J. (2007). The relations among narcissism, selfesteem, and delinquency in a sample of at-risk adolescents. Journal of Adolescence, 30, 933942. doi:10.1016/j.adolescence.2006.12.003

Barry, C. T., Frick, P. J., \& Killian, A. L. (2003). The relation of narcissism and self-esteem to conduct problems in children: A preliminary investigation. Journal of Clinical Child and Adolescent Psychology, 32, 139-152. doi:10.1207/S15374424JCCP3201_13

Boduszek, D., \& Debowska, A. (2016). Critical evaluation of psychopathy measurement (PCL$\mathrm{R}$ and SRP-III/SF) and recommendations for future research. Journal of Criminal Justice, 44, 1-12. doi:10.1016/j.crimjus.2015.11.004

Boduszek, D., Debowska, A., Dhingra, K., \& DeLisi, M. (2016). Introduction and validation of Psychopathic Personality Traits Scale (PPTS) in a large prison sample. Journal of Criminal Justice, 46, 9-17. doi:10.1016/j.crimjus.2016.02.004

Brinkley, C. A., Schmitt, W. A., Smith, S. S., \& Newman, J. P. (2001). Construct validation of a self-report psychopathy scale: Does Levenson's self-report psychopathy scale measure the same constructs as Hare's psychopathy checklist-revised? Personality and Individual Differences, 31, 1021-1038. doi:10.1016/S0191-8869(00)00178-1

Caputo, A., Frick, P., \& Brosky, S. (1999). Family violence and juvenile sex offending: The potential role of psychopathic traits and negative attitudes toward women. Criminal Justice and Behavior, 26, 338-356. doi:10.1177/0093854899026003004

Coid, J., \& Yang, M. (2011). The impact of psychopathy on violence among the household population of Great Britain. Social Psychiatry and Psychiatric Epidemiology, 46, 473-480. doi:10.1007/s00127-010-0212-4

Colins, O. F., van Damme, L., Andershed, H., Fanti, K. A., \& DeLisi, M. (2017). Self-reported psychopathic traits and antisocial outcomes in detained girls: A prospective study. Youth Violence and Juvenile Justice, 15, 138-153. doi:10.1177/1541204015619659

Connolly, E. J., Al-Ghamdi, M. S., Kobeisy, A. N., Alqurashi, F., Schwartz, J. A., \& Beaver, K. M. (2017). Identifying latent classes of antisocial behavior among youth from Saudi Arabia: An assessment of the co-occurrence between aggression, psychopathy, low self-control, and delinquent behavior. Youth Violence and Juvenile Justice, 15(3), 219-239. doi:10.1177/1541204016639349

Cooke, D. J., \& Michie, C. (2001). Refining the construct of psychopathy: Towards a hierarchical model. Psychological Assessment, 13, 171-188. doi:10.1037/1040-3590.13.2.171

Corrado, R., Vincent, G., Hart, S., \& Cohen, I. (2004). Predictive validity of the psychopathy checklist: Youth version for general and violent recidivism. Behavioral Sciences and the Law, 22, 5-22. doi:10.1002/bsl.574

Corrado, R. R., McCuish, E. C., Hart, S. D., \& DeLisi, M. (2015). The role of psychopathic traits and developmental risk factors on offending trajectories from early adolescence to adulthood: A prospective study of incarcerated youth. Journal of Criminal Justice, 43(4), 357-368. doi:10.1016/j.crimjus.2015.04.007 
Cottle, C., Lee, R., \& Heilbrun, K. (2001). The prediction of criminal recidivism in juveniles: A meta-analysis. Criminal Justice and Behavior, 28, 367-394. doi:10.1177/0093854801028003005

De Vogel, V., \& Lancel, M. (2016). Gender differences in the assessment and manifestation of psychopathy: Results from a multicenter study in forensic psychiatric patients. International Journal of Forensic Mental Health, 15(1), 97-110. doi:10.1080/14999013.2016.1138173

DeLisi, M., Dansby, T., Peters, D. J., Vaughn, M. G., Shook, J. J., \& Hochstetler, A. (2014). Fledgling psychopathic features and pathological delinquency: New evidence. American Journal of Criminal Justice, 39, 411-424. doi:10.1007/s12103-013-9218-2

DeVellis, R. (1991). Scale development: Theory and aplications. London: SAGE.

Douglas, K. S., Epstein, M. E., \& Poythress, N. G. (2008). Criminal recidivism among juvenile offenders: Testing the incremental and predictive validity of three measures of psychopathic features. Law and Human Behavior, 32, 423-438. doi:10.1007/s10979-007-9114-8

Edens, J. F., Poythress, N. G., \& Lilienfeld, S. O. (1999). Identifying inmates at risk for disciplinary infractions: A comparison of two measures of psychopathy. Behavioral Sciences and the Law, 17, 435-443. doi:10.1002/(SICI)1099-0798(199910/12)17:4<435:: AID-BSL356>3.0.CO;2-Z

Edens, J. F., Campbell, J. S., \& Weir, J. M. (2007). Youth psychopathy and criminal recidivism: A meta-analysis of the Psychopathy Checklist measures. Law and Human Behavior, 31, 53-75. doi:10.1007/s10979-006-9019-y

Edens, J. F., Hart, S. D., Johnson, D. W., Johnson, J., \& Olver, M. E. (2000). Use of the Personality Assessment Inventory to assess psychopathy in offender populations. Psychological Assessment, 12, 132-139. doi:10.1037//1040-3590.12.2.132

Essau, C. A., Sasagawa, S., \& Frick, P. J. (2006). Callous-Unemotional traits in a community sample of adolescents. Assessment, 13, 454-469. doi:10.1177/1073191106287354

Feilhauer, J., Cima, M., \& Arntz, A. (2012). Assessing callous-unemotional traits across different groups of youths: Further cross-cultural validation of the Inventory of Callous-Unemotional Traits. International Journal of Law and Psychiatry, 35, 251-262. doi:10.1016/j.ijlp.2012.04.002

Forth, A., Kosson, D., \& Hare, R. (2003). Hare Psychopathy Checklist: Youth Version (PCL: YV): Technical manual. Toronto, ON: Multi-Health Systems.

Frick, P., \& Hare, R. (2001). The antisocial process screening device. Toronto, ON: MultiHealth Systems.

Frick, P., Ray, J., Thornton, L., \& Kahn, R. (2014). Can callous-Unemotional traits enhance the understanding, diagnosis, and treatment of serious conduct problems in children and adolescents? A comprehensive review. Psychological Bulletin, 140, 1-57. doi:10.1037/a0033076

Gentile, B., Miller, J. D., Hoffman, B. J., Reidy, D. E., Zeichner, A., \& Campbell, W. K. (2013). A test of two brief measures of grandiose narcissism: The Narcissistic Personality Inventory (NPI)-13 and NPI-16. Psychological Assessment, 25, 1120-1136. doi:10.1037/a0033192

Golmaryami, F. N., \& Barry, C. T. (2010). The associations of self-reported and peer-reported relational aggression with narcissism and self-esteem among adolescents in a residential setting. Journal of Clinical Child \& Adolescent Psychology, 39, 128-133. doi:10.1080/15374410903401203

Goodkind, S., Wallace, J. M., Shook, J. J., Bachman, J., \& O’Malley, P. (2009). Are girls really becoming more delinquent? Testing the gender convergence hypothesis by race and ethnicity, 1976-2005. Child and Youth Services Review, 31, 885-895. doi:10.1016/j.childyouth.2009.04.002

Hare, R. (2003). The hare psychopathy checklist-revised (2nd ed.). Toronto, ON: Multi-Health Systems.

Hare, R. D. (1996). Psychopathy: A clinical construct whose time has come. Criminal Justice and Behavior, 23, 25-54. doi:10.1177/0093854896023001004

Hazelwood, L. L. (2006). Gender differences in a prototypical analysis of psychopathy (Unpublished Masters thesis). University of North Texas, Denton, TX. Retrieved from http://digital.library.unt.edu/ark:/67531/metadc5371/m2/1/high_res_d/thesis.pdf 
IBM Corp. (2016). IBM SPSS Statistics (Version 24). Chicago, IL: SPSS Inc.

Jackson, R., Rogers, R., Neumann, C. S., \& Lambert, P. (2002). Psychopathy in women: An investigation of its underlying dimensions. Criminal Justice and Behavior, 29, 692-704. doi: $10.1177 / 009385402237922$

Kahn, R. E., Byrd, A. L., \& Pardini, D. A. (2013). Callous-unemotional traits robustly predict future criminal offending in young men. Law and Human Behavior, 37, 87-97. doi:10.1037/b0000003

Kimonis, E. R., Frick, P. J., Skeem, J., Marsee, M. A., Cruise, K., Munoz, L. C.,... Morris, A. S. (2008). Assessing callous-unemotional traits in adolescent offenders: Validation of the Inventory of Callous-Unemotional Traits. International Journal of Law and Psychiatry, 31, 241-252. doi:10.1016/j.ijlp.2008.04.002

Kimonis, E. R., Kennealy, P. J., \& Goulter, N. (2016). Does the self-report inventory of callous-unemotional traits predict recidivism? Psychological Assessment, 28, 1616-1624. doi:10.1037/pas0000292

Kreis, M. K. F., \& Cooke, D. J. (2011). Capturing the psychopathic female: A prototypicality analysis of the Comprehensive Assessment of Psychopathic Personality (CAPP) across gender. Behavioral Sciences \& the Law, 29, 634-648. doi:10.1002/bsl.1003

Kroner, D. G., \& Loza, W. (2001). Evidence for the efficacy of self-report in predicting nonviolent and violent criminal recidivism. Journal of Interpersonal Violence, 16, 168-177. doi:10.1177/088626001016002005

Lanctôt, N., \& Le Blanc, M. (2002). Explaining deviance by adolescent females. In M. Tonry (Ed.), Crime and justice (Vol. 29, pp. 113-202). Chicago, Illinois, USA: University of Chicago Press.

Langström, N., \& Grann, M. (2002). Psychopathy and violent recidivism among young criminal offenders. Acta Psychiatrica Scandinavica, 106, 86-92. doi:10.1034/j.1600-0447.106.s412.19.x

Loeber, R., Jennings, W. G., Ahonen, L., Piquero, A. R., \& Farrington, D. P. (2017). Female delinquency from childhood to young adulthood. New York, NY: Springer.

Lynam, D. R. (1997). Pursuing the psychopath: Capturing the fledgling psychopath in a nomological net. Journal of Abnormal Psychology, 106, 425-438. doi:10.1037/0021-843X.106.3.425

Maltz, M. D. (1984). Recidivism. Orlando, FL: Academic Press.

McCuish, E. C., Corrado, R. R., Hart, S. D., \& DeLisi, M. (2015). The role of symptoms of psychopathy in persistent violence over the criminal career into full adulthood. Journal of Criminal Justice, 43, 345-356. doi:10.1016/j.crimjus.2015.04.006

McKeown, A. (2010). Female offenders: Assessment of risk in forensic settings. Aggression and Violent Behavior, 15, 422-429. doi:10.1016/j.avb.2010.07.004

Miller, J. D., Jones, S. E., \& Lynam, D. R. (2011). Psychopathic traits from the perspective of self and informant reports: Is there evidence for a lack of insight? Journal of Abnormal Psychology, 120, 758-764. doi:10.1037/a0022477

Nunnally, J., \& Bernstein, I. (1994). Psychometric theory (3rd ed.). New York, NY: McGraw-Hill.

Odgers, C. L., Reppucci, N. D., \& Moretti, M. M. (2005). Nipping psychopathy in the bud: An examination of the convergent, predictive, and theoretical utility of the PCL-YV among adolescent girls. Behavioral Sciences and the Law, 23, 743-763. doi:10.1002/bsl.664

Olver, M. E., Stockdale, K. C., \& Wormith, J. S. (2009). Risk assessment with young offenders: A meta-analysis of three assessment measures. Criminal Justice and Behavior, 36, 329-353. doi:10.1177/0093854809331457

Patton, J. H., Stanford, M. S., \& Barratt, E. S. (1995). Factor structure of the Barratt Impulsiveness Scale. Journal of Clinical Psychology, 51, 768-774. doi:10.1002/1097-4679 (199511)51:6<768::AID-JCLP2270510607>3.0.CO;2-1

Pechorro, P., Gentile, B., Ray, J., Nunes, C., \& Gonçalves, R. (2016). Adaptation of the Narcissistic Personality Inventory among Portuguese juvenile offenders. Psychology, Crime \& Law, 22, 495-511. doi:10.1080/1068316X.2016.1168421 
Pechorro, P., Hidalgo, V., Nunes, C., \& Jiménez, L. (2016). Confirmatory factor analysis of the Antisocial Process Screening Device: Self-Report among incarcerated male juvenile offenders. International Journal of Offender Therapy and Comparative Criminology, 60, 1856-1872. doi:10.1177/0306624X15588903

Pechorro, P., Maroco, J., Ray, J., \& Gonçalves, R. (2015). Psychometric properties of the Barratt Impulsiveness Scale version 11 among a Portuguese sample of incarcerated juvenile offenders. Psychology, Crime \& Law, 21, 854-870. doi:10.1080/1068316X.2015.1054386

Pechorro, P., Oliveira, J. P., Gonçalves, R., \& Jesus, S. (2018). Propriedades psicométricas de uma versão reduzida da Escala de Impulsividade de Barratt - 11 numa amostra escolar de adolescentes portugueses [Psychometric properties of a short version of the Barratt Impulsiveness Scale - 11 among a school sample of Portuguese adolescentes]. Revista Iberoamericana de Diagnostico y Evaluacion Psicologica, 47, 157-170. doi:10.21865/ RIDEP47.2.11

Pechorro, P., Ray, J., Barroso, R., Maroco, J., \& Gonçalves, R. (2016). Validation of the Inventory of Callous-Unemotional Traits among a Portuguese sample of detained juvenile offenders. International Journal of Offender Therapy and Comparative Criminology, 60, 349-365. doi:10.1177/0306624X14551256

Porter, S., Woodworth, M., Earle, J., Drugge, J., \& Boer, D. (2003). Characteristics of sexual homicides committed by psychopathic and nonpsychopathic offenders. Law and Human Behavior, 27, 459-470. doi:10.1023/A:1025461421791

Raskin, R., \& Terry, H. (1988). A principal-components analysis of the Narcissistic Personality Inventory and further evidence of its construct validity. Journal of Personality and Social Psychology, 54, 890-902. doi:10.1037/00223514.54.5.890

Ray, J., Pechorro, P., \& Gonçalves, R. (2016). A comparison of self-report measures of callous-unemotional traits among incarcerated youth: Associations with aggression, conduct disorder, and offending behavior. Criminal Justice and Behavior, 43, 1293-1309. doi:10.1177/0093854815628027

Roberts, A. L., \& Coid, J. W. (2007). Psychopathy and offering behavior: Findings from the national survey of prisoners in England and Wales. Journal of Forensic Psychiatry \& Psychology, 18, 23-43. doi:10.1016/j.ijlp.2009.02.008

Rowe, R. (2002). Predictors of criminal offending: Evaluating measures of risk/needs, psychopathy, and disruptive behaviour disorders (Unpublished doctoral dissertation). Department of Psychology, Carleton University, Ottawa, CA.

Salekin, R. (2008). Psychopathy and recidivism from mid-adolescence to young adulthood: Cumulating legal problems and limiting life opportunities. Journal of Abnormal Psychology, 117, 386-395. doi:10.1037/0021-843X.117.2.386

Salekin, R. T., Rogers, R., \& Sewell, K. W. (1996). A review and meta-analysis of the Psychopathy Checklist and Psychopathy Checklist-Revised: Predictive validity of dangerousness. Clinical Psychology: Science and Practice, 3, 203-215. doi:10.1111/j.14682850.1996.tb00071

Schmidt, F., McKinnon, L., Chattha, H. K., \& Brownlee, K. (2006). Concurrent and predictive validity of the Psychopathy Checklist: Youth Version across gender and ethnicity. Psychological Assessment, 18, 393-401. doi:10.1037/1040-3590.18.4.393

Simões, M. R. (2000). Investigações no âmbito da Aferição Nacional do Teste das Matrizes Progressivas Coloridas de Raven [Investigations in the context of the national standardization of the Raven Coloured Progressive Matrices test]. Lisboa, Portugal: Fundação Calouste Gulbenkian.

Theobald, D., Farrington, D. P., Coid, J. W., \& Piquero, A. R. (2016). Are male perpetrators of intimate partner violence different from convicted violent offenders? Examination of 
psychopathic traits and life success in males from a community survey. Journal of Interpersonal Violence, 31(9), 1687-1718. doi:10.1177/0886260515569061

Thomson, N. D., Towl, G. J., \& Centifanti, L. C. M. (2015). The habitual female offender inside: How psychopathic traits predict chronic prison violence. Law and Human Behavior, 40, 257-269. doi:10.1037/lhb0000178

Tuente, S. K., De Vogel, V., \& Stam, J. (2014). Exploring the criminal behavior of women with psychopathy: Results from a multicenter study into psychopathy and violent offending in female forensic psychiatric patients. International Journal of Forensic Mental Health, 13, 311-322. doi:10.1080/14999013.2014.951105

Vasconcelos, A., Malloy-Diniz, L., \& Correa, H. (2012). Systematic review of psychometric properties of Barratt Impulsiveness Scale version 11 (BIS-11). Clinical Neuropsychiatry, 9, 61-74. doi:10.1590/1516-4446-2014-1599

Vaughn, M. G., Howard, M. O., \& DeLisi, M. (2008). Psychopathic personality traits and delinquent careers: An empirical examination. International Journal of Law and Psychiatry, 31, 407-416. doi:10.1016/j.ijlp.2008.08.001

Vaughn, M. G., Newhill, C. E., DeLisi, M., Beaver, K. M., \& Howard, M. O. (2008). An investigation of psychopathic features among delinquent girls violence, theft, and drug abuse. Youth Violence and Juvenile Justice, 6, 240-255. doi:10.1177/1541204007312298

Vincent, G. M., Odgers, C. L., McCormick, A. V., \& Corrado, R. R. (2008). The PCL:YV and recidivism in male and female juveniles: A follow-up into young adulthood. International Journal of Law and Psychiatry, 31, 287-296. doi:10.1016/j.ijlp.2008.04.012

Vitacco, M. J., Neumann, C. S., \& Jackson, R. L. (2005). Testing a four-factor model of psychopathy and its association with ethnicity, gender, intelligence, and violence. Journal of Consulting and Clinical Psychology, 73, 466-476. doi:10.1037/0022-006X.73.3.466

Walters, G. D. (2003). Predicting institutional adjustment and recidivism with the psychopathy checklist factor scores: A meta-analysis. Law and Human Behavior, 27, 541-558. doi:10.1023/A:1025490207678

Walters, G. D., Knight, R. A., Grann, M., \& Dahle, K.-P. (2008). Incremental validity of the psychopathy checklist facet scores: Predicting release outcome in six samples. Journal of Abnormal Psychology, 177, 396-405. doi:10.1037/0021-843X.117.2.396

Whitten, T., McGee, T., Homel, R., Farrington, D., \& Ttofi, M. (2017). Disentangling operationalizations of persistent offending. Journal of Criminal Justice, 52, 22-33. doi:10.1016/j.jcrimjus.2017.07.001

Wynn, R., Høiseth, M. H., \& Pettersen, G. (2012). Psychopathy in women: Theoretical and clinical perspectives. International Journal of Women's Health, 4, 257-263. doi:10.2147/ IJWH.S25518

Zara, G., \& Farrington, D. P. (2016). Criminal recidivism: Explanation, prediction and prevention. New York, NY: Routledge. 